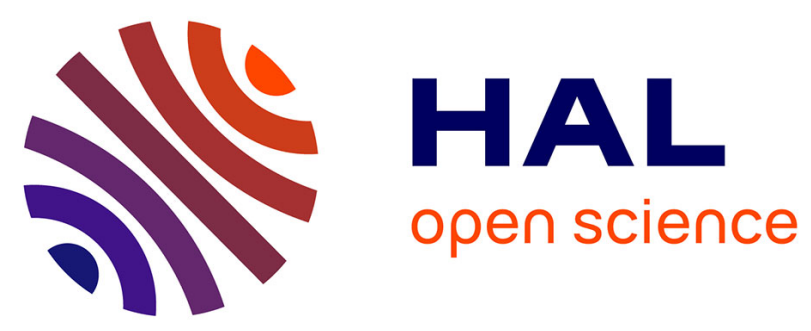

\title{
Long Term Forecast of Local Electrical Demand and Evaluation of Future Impacts on the Electricity Distribution Network
}

Nicolas Kong, Maxence Bocquel, Thibaut Barbier, Robin Girard, Elena Magliaro, Georges Kariniotakis, Guillaume Pelton, Pierre Cauchois

\section{To cite this version:}

Nicolas Kong, Maxence Bocquel, Thibaut Barbier, Robin Girard, Elena Magliaro, et al.. Long Term Forecast of Local Electrical Demand and Evaluation of Future Impacts on the Electricity Distribution Network. CIRED 2017, Jun 2017, Glascow, United Kingdom. pp.0743. hal-01513138

\author{
HAL Id: hal-01513138 \\ https://hal.science/hal-01513138
}

Submitted on 24 Apr 2017

HAL is a multi-disciplinary open access archive for the deposit and dissemination of scientific research documents, whether they are published or not. The documents may come from teaching and research institutions in France or abroad, or from public or private research centers.
L'archive ouverte pluridisciplinaire HAL, est destinée au dépôt et à la diffusion de documents scientifiques de niveau recherche, publiés ou non, émanant des établissements d'enseignement et de recherche français ou étrangers, des laboratoires publics ou privés. 


\section{LONG TERM FORECAST OF LOCAL ELECTRICAL DEMAND AND EVALUATION OF FUTURE IMPACTS ON THE ELECTRICITY DISTRIBUTION NETWORK}

\author{
Nicolas KONG \\ Maxence BOCQUEL \\ Enedis - France \\ nicolas.kong@enedis.fr \\ maxence-externe.bocquel@enedis.fr
}

\author{
Thibaut BARBIER \\ Robin GIRARD \\ Elena MAGLIARO \\ Georges KARINIOTAKIS \\ Mines Paris Tech - France \\ thibaut.barbier@mines-paritech.fr
}

\author{
Guillaume PELTON \\ Pierre CAUCHOIS \\ Enedis - France \\ guillaume.pelton@enedis.fr \\ pierre-externe.cauchois@enedis.fr
}

\begin{abstract}
Enedis (France's main electricity DSO) and Mines Paris Tech are working on a new method called MOSAIC that aims at assessing the impact of long term local development projects on the electrical grid.

The MOSAIC method uses a bottom-up simulation tool able to determine the current and future consumption and production load curve of an area. The consumption and production simulators are based on a multi-level data model that makes it possible to run a simulation even if some data are missing.

The simulation parameters are calibrated by comparing the simulated load curves with observations on MV feeders (for the consumption simulator) and on 100 renewable energy producers (PV and WP).

Once the simulators are calibrated for the current situation, the load curve of each development scenario of the area is estimated (the evolution scenarios are proposed by the local government, based on infeed growing, building projects ...).

Enedis and Mines Paris Tech are now working on linking the load curve simulators with more traditional electrical study tools. From the simulated load curve, we estimate the most likely maximal power of the grid infrastructures and use these values in the load flow tool called ERABLE to evaluate the impact of the scenarios on the grid. Initial tests were successful and this method will be further developed in 2017 on ten experimentation projects in France. Each project will help to develop new functionalities such as integrating Demand Response or electrical vehicle infrastructures.
\end{abstract}

\section{INTRODUCTION}

In the last few years, local governments have gain many skills regarding the energy transition. Indeed, most of the necessary actions requested by the recent laws on the energy transition in France should be pursued at local level by local governments. Therefore, they are becoming to see energy as a crucial issue to be considered during urban development projects.

At the same time, the features of electricity consumption are changing due to many factors such as renovations of old neighborhoods, construction of new and highly efficient buildings, growth in local renewable energy production and creation of electric car charging infrastructure. Local authorities need to correctly anticipate both the impact of these evolutions and the need for investments to succeed in their energy transition. Such a target requires a close collaboration between local authorities and their DSO: if the impact of urban planning decisions on the grid is assessed early on a project life cycle, solutions can be found in order to minimize new investment needs. This approach is essential to create sustainable cities.

For that reason, Enedis and Mines Paris Tech are developing a new method, named MOSAIC, which uses a bottom-up electric load curve simulator. With MOSAIC, Enedis will be able to assess the impacts on the electrical grid of different city-development-scenarios, at different time scales.

\section{SIMULATION OF THE ELECTRIC LOAD CURVE OF AN AREA}

The MOSAIC method uses a bottom-up load curve simulator developed by Mines Paris Tech [5]. The first step to perform a simulation is to be able to correctly model the current and the future study area.

\subsection{Modeling of the area}

The simulator evaluates the load curve of each customer (residential, tertiary as well as solar PV and Wind Power producer) before aggregating them at the relevant scale. This requires having a significant amount of information on the study area:

- For simulating consumption load curve: type of premises (residential, offices, shops etc.), surface area, ceiling height, age of the building or energy efficiency, performance level, presence of electric heating, electric water heater and/or electric air conditioning, position of the premises on the building etc.

- For simulating the production load curve: GPS coordinates of the producer, installed power, type of production (PV or WP) and characteristic of the infrastructure (orientation, technology etc.).

Description of a project with the MOSAIC method Even if the simulator potentially requires a lot of input data, an accurate description of every consumer and producer of the area is not necessary. The study area is described in MOSAIC using a multi-layer model: each 
consumer/producer is part of a "block" and each block is part of a project (see Figure 1).

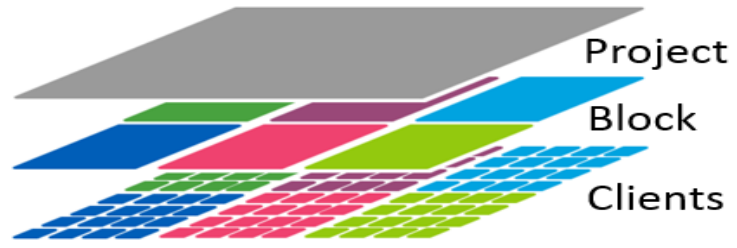

Figure 1 - Description of an area in MOSAIC

When a piece of information is missing, the simulator uses instead default values, first at block level when available, second at project level if needed. This multi-layer organization then makes it possible to simulate an area where some data are missing. The quality of the result will depend on how precise the area is described.

\section{The MOSAIC method can be used for two main types} of situations

There are two use cases in which MOSAIC can be useful for DSOs and for local governments:

1. Evolution of an existing area. The area is already connected to the electrical grid, therefore the goal of the study is to evaluate the deepness of grid modifications needed by change of power demand.

2. Creation of a new area. The electrical grid will be created from scratch. The goal will be to define the infrastructures necessary to connect the area (secondary substations, MV Feeder etc.).

\section{Description of the reference situation}

Simulating the current situation is interesting for the first case study (evolution of an existing area) as it's useful to estimate the current load curve of each secondary substation and to evaluate the gain of power that could be made by refurbishing the existing buildings. The current situation is called the "reference situation" and it will be used as a base line for comparing future scenarios.

Enedis and Mines Paris Tech have assessed many potential sources of data describing the current situation.

Census data are open-access on the French Statistics Office (INSEE) website and were therefore the first source of data to be tested with MOSAIC. They describe quite precisely the residential building of a designated area, however there is very little information on the location of these buildings (we only know to what district they belong).

Recently acquired MAJIC (Land-registry) data are more convenient than census data as they provide a more detailed description of buildings including their address. Coupled with Enedis' database, they will be used from now on.

Enedis own database includes customer information system (CIS). For all customers, CISs store their electrical connection to the grid, their annual consumption, their type of contract, and their contracted power. Most of DSOs have similar data [1]

INSEE or MAJIC database need to be coupled with Enedis' database in order to simulate the current load curve of a substation or an electrical feeder.

Mines Paris Tech therefore developed an efficient method for matching the INSEE and Enedis' residential customers [4].

The MAJIC/Enedis matching is easier than the INSEE/Enedis matching, as it's possible to compare addresses. Unfortunately, the two database have different ways of recording addresses. Mines Paris Tech developed an algorithm able to homogenize addresses structures between the two databases and to correct spelling mistakes in street names.

This method has been tested on $22 \mathrm{MV}$ feeders (around 135,000 customers) and only $3 \%$ of the customers could not be match with a MAJIC data:

\begin{tabular}{|c|c|c|c|}
\hline Direct match & $\begin{array}{c}\text { Matched } \\
\text { after } \\
\text { correcting } \\
\text { the address }\end{array}$ & $\begin{array}{c}\text { Enedis } \\
\text { customer not } \\
\text { matched }\end{array}$ & $\begin{array}{c}\text { MAJIC data } \\
\text { not matched }\end{array}$ \\
\hline $47 \%$ & $42 \%$ & $3 \%$ & $7,35 \%$ \\
\hline \multicolumn{4}{|c|}{ Figure 2 - Quality statistics on the matching of 135 O00 Enedis } \\
customers with MAJIC data
\end{tabular}

For the second use case (creation of a new area) there is no need to simulate the current situation. The reference scenario is therefore one of the potential scenarios (usually the business-as-usual evolution).

\section{Description of future evolutions}

The goal of the MOSAIC method is to compare the impact on the electrical grid of different evolution scenarios of the study area.

Evolution scenarios are proposed by the local government. The current simulator is able to simulate building destruction, building refurbishment (with thermal efficiency improvement), creation of new buildings, development of renewable energy sources, changes in the energy vector used for space heating and cooling, and improvement in street lightning efficiency.

In 2017, Enedis and Mines Paris Tech will work to add other potential evolutions in the scenarios such as the development of electric car charging stations, or Demand Response.

\subsection{Electric load curve simulation}

\section{Description of the models}

The electric load curve simulation is performed with a compromise between physical and statistical models of appliances, consumers and buildings. It allows simulating in a bottom up way with a short computation time: few minutes to simulate the electricity demand of thousands of customers for one year at one hour time step. A complete description of the structure of the model is described in [5].

\section{Evaluation of results and calibration}

The results given by the model have to be evaluated by comparing them to reference values. Default values are 
calibrated in order to minimize the gap between the results and the reference.

The first evaluation we did was to check if all the devices were correctly simulated by comparing them to campaign measurement results or the literature. In Figure 3 are examples of different checks for use laundry. In the example of laundry we compared our values to the French campaign described in [6]. We did this kind of evaluation for all uses, and all type of customer.

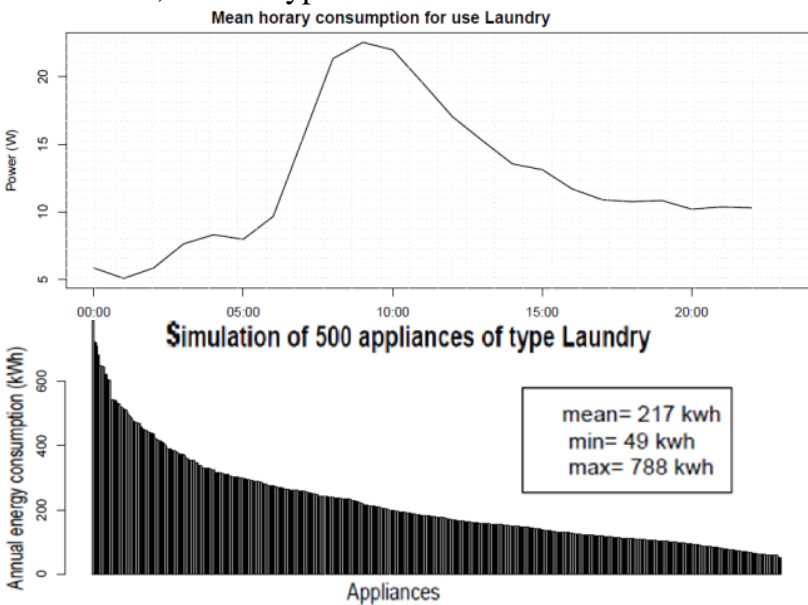

Figure 3 - Example of simulation characteristics for use laundry.

Another evaluation was done by comparing aggregated load curve from feeders' measurement and simulation results. Thanks to Enedis' CIS, and the matching with land registry data described in 1.1, we can have the list of premises per electric feeder. We then remove diffuse renewable production thanks to the production load curve simulator (1.3).

Then, we can perform a simulation for a feeder.

Without any calibration, result can be seen in Figure 4. We clearly see that the simulated load curve (blue) is higher than the measured one: many influent parameters, such as temperature target for electric heaters or mean thermal resistance of building, were set by default.

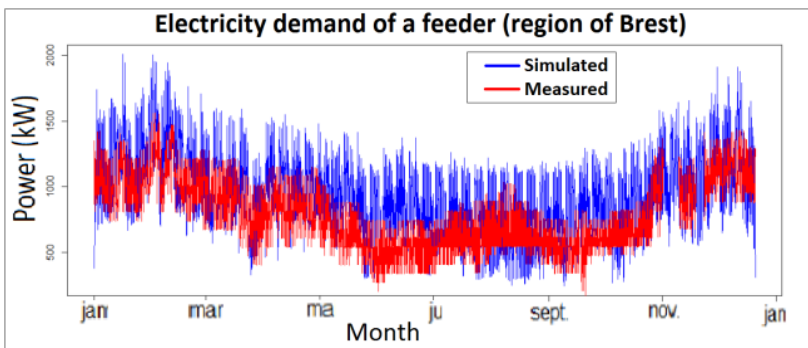

Figure 4 - Example of simulation and measurement of a feeder with default parameters (before calibration)

The most influent parameters can be chosen, and tuned in order to minimize the RMSE (root mean square errors). In our case we choose electric heaters temperature target and mean thermal resistance of buildings.

The result after calibration is depicted in Figure 5. The two load curves are closer, the RMSE was minimized by adjusting the two parameters.

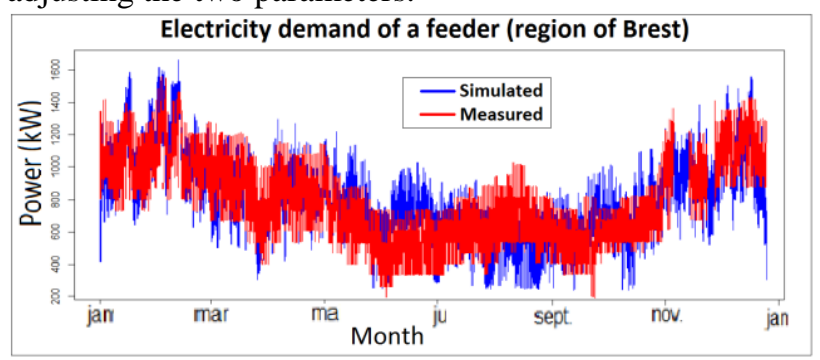

Figure 5 - Example of simulation and measurement of a feeder with calibrated values.

Our method allows to calibrate the parameters of the model learning from measurements. It is then possible to simulate either evolution of an existing area or a new area by using these calibrated values. We use this approach in the following case study.

\subsection{Production load curve simulation}

\section{Description of the models}

MINES ParisTech has developed models to compute the normalized renewable energy production on a region by using meteorological data such as the horizontal irradiation, temperature and wind speed. These data can be retrieved from either measurement or reanalysis data.

For the production from photovoltaic panels (PV) we use the Muneer model [2] to compute the diffuse part of the radiation over the tilted solar module and a physical model for the module itself. It is possible to choose a predefined statistical distribution for inclination and orientation of panels on roofs. Several technologies and integration architectures are modelled and the user can select the characteristics of the panels.

For the wind production we can choose specific parameters of the technology of the wind turbine, the altitude of the hub to extrapolate wind speed data using a logarithmic profile. We have also the possibility to specify a wind power curve, to use a default one or to compute a power curve using the region wind speed measures, the installed capacity and the historical production on the region. This last option allows locally calibrating the relationship between wind speed and production and improving the production simulation result.

This model is particularly useful to simulated diffuse production before the calibration of the electric load curve simulator. It is also of a great interest to test different local renewable production penetration rates and its influence on electrical grid sizing [3].

\section{Evaluation of results and calibration}

Enedis collects some individual measurement of solar and wind farm and individual PV producers.

Knowing the location and the installed power of each producer, it is possible to compare simulation and measurements. In Figure 6 we plot an example of 
production simulated and measured.

Simulated and mesured PV production for a 12kW producer in Paris

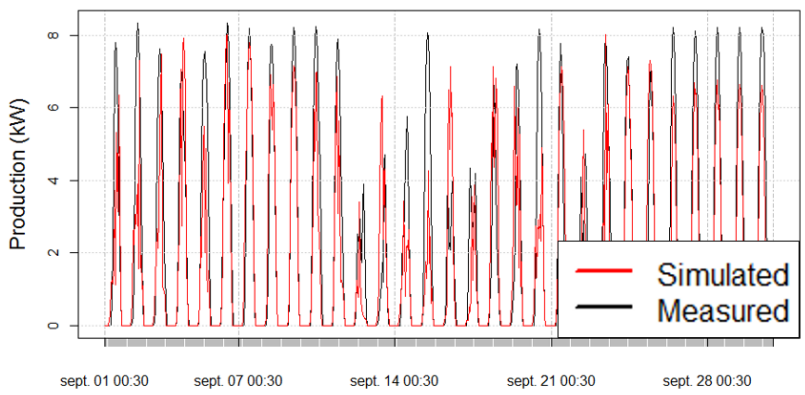

Figure 6 - Simulated and measured PV production for a $12 \mathrm{~kW}$ producer in Paris

As it is difficult to collect information at large scale about the installed technology, the precise orientation and inclination of panels, the shadow effects (especially for PV on roofs), we set by default the different values according to national statistics. In the same way as simulation of electricity demand, we can tune the different parameters in order to get a better fit with measurements.

\section{SIMULATION RESULTS}

\subsection{Result analysis on the MOSAIC HMI}

MOSAIC Human Machine Interface (HMI) provides many functionalities for the visualization of the simulation's results: load curve analysis, energy analysis, load duration curve.

The first analysis module shows simulated load curves either in an aggregated way or with a separation by usage, substations, or bulding block.

This module provides important information on the diversity factor of the area. When assessing the impact of connecting new building on the grid, it's important to determine what would be the most likely peak demand value for each grid infrastructure. Usually this value is estimated by adding the maximum power of each customer and using a default value for a diversity factor between the residential customers

MOSAIC is able to find the most probable maximum load of an area/building depending on individual consumer consumption, but as well on diversity factor. Indeed maximum consumption of a building is not the sum of individual consumptions. For example in figure 7 , the maximum power demand is $171 \mathrm{~kW}$, which is $15 \%$ smaller than the sum of the residential power peak $(73 \mathrm{~kW})$ and the tertiary power peak $(127 \mathrm{~kW})$.

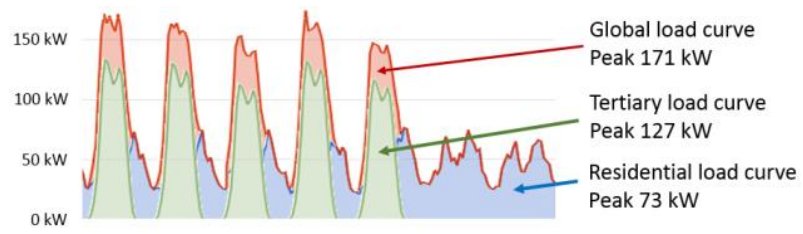

Figure 7 - Load curve of residential and tertiary customers simulated by the MOSAIC method
Furthermore, comparing consumption and production load curves made for many meteorological scenarios gives information on the likeliness of some critical situations such as a $100 \%$ production with very little consumption. Finally if the simulator is not able to simulate some very specific consumers or producers, it's still possible to take them into consideration by uploading directly their load curves (got from observations or from another simulator).

\subsection{Characterization of the most likely peak demand}

The French electrical grid is designed to be able to resist in critical situations such as very cold temperatures (demand is heavily dependent on the temperature due to high use of electric heating).

In this context, Enedis is designing its grid for severe temperature conditions to be able to resist power value that are on average reached around 1 day per year (power value called $\mathrm{P}_{\mathrm{tmb}}$ ).

The goal of the MOSAIC method is to evaluate the impact on the grid of the changes in the area. It's therefore necessary to translate the results of the simulator into power values that can be used in an electrical simulator software.

Enedis and Mines Paris Tech are currently testing different methods to determine the power value to be used for impact assessment. In the first use case, the simulation results are aggregated at a gird scale (MV/LV substation) and they are represented on a load duration curve (see Figure 8). By running the simulation for many years of weather data and by using this load duration curve, it's possible to estimate $\mathrm{P}_{\mathrm{tmb}}$ for each substation. What's interesting with this method is that it gives the contribution of each substation to the global power peak and not their individual maximum (different due to the diversity effect). Furthermore, when it's too early in the project life to be able to locate precisely a future consumer or producer, a Monte Carlo method is used to locate them.

In use case $2, \mathrm{P}_{\mathrm{tmb}}$ is estimated the same way but at the scale of the building (or building block).

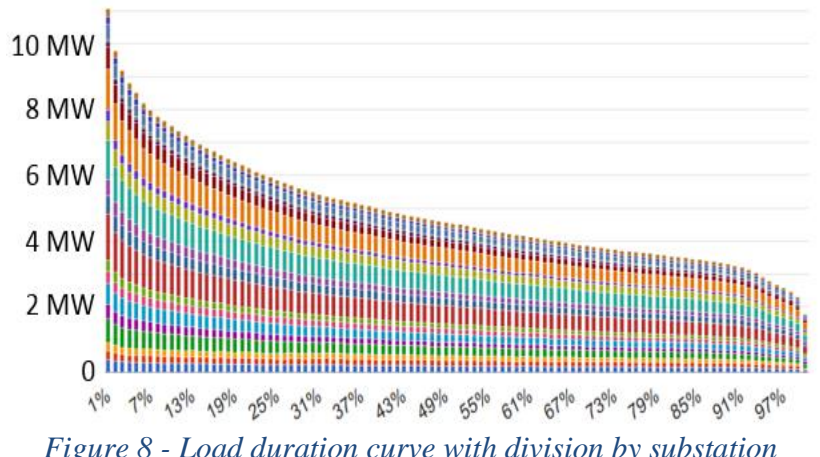

Mines Paris Tech and Enedis are now working on the automation of this process in order to directly get the power value with a chosen probability. 


\section{EVALUATION OF THE IMPACT ON THE GRID}

The last step in the MOSAIC method is to evaluate the impact on the grid of the area evolutions. This step is still under development and it will be done using Enedis' load flow computation tool ERABLE (based on the software PowerFactory by DIgSILENT). It will allow to highlight grid constraints (voltage/current) for the diversity of scenarios submitted based on load calculated at $\mathrm{P}_{\mathrm{tmb}}$.

Relevant and comprehensive representation of the results of these calculations is still under development.

\section{FIRST RESULTS ON MV FEEDERS}

The matching method between premises per electric feeder was applied in a case study of 10 feeders in Brest, France. The sample characteristics are illustrated in table 1.

Table 1 Characteristics of the 10 feeders data set used

\begin{tabular}{|l|l|l|l|}
\hline \multicolumn{1}{|c|}{ Characteristics } & \multicolumn{1}{|c|}{$\begin{array}{c}\text { Min } \\
\text { value }\end{array}$} & $\begin{array}{l}\text { Mean } \\
\text { value }\end{array}$ & Max value \\
\hline $\begin{array}{l}\text { Number of customers } \\
\text { supplied }\end{array}$ & 357 & 751 & 1471 \\
\hline $\begin{array}{l}\text { Fraction of residential } \\
\text { consumption }\end{array}$ & $34 \%$ & $62 \%$ & $91 \%$ \\
\hline
\end{tabular}

We apply the same method for calibrating the main influence default parameters as described in 1.2.

Thanks to the simulation of electricity feeders and MV/LV substations with MOSAIC, we perform a large range of simulations with various meteorological conditions. In Figure 9 we plot the overpass of the reference power of a $\mathrm{MV} / \mathrm{LV}$ substation with the meteorological conditions of the past 30 years.

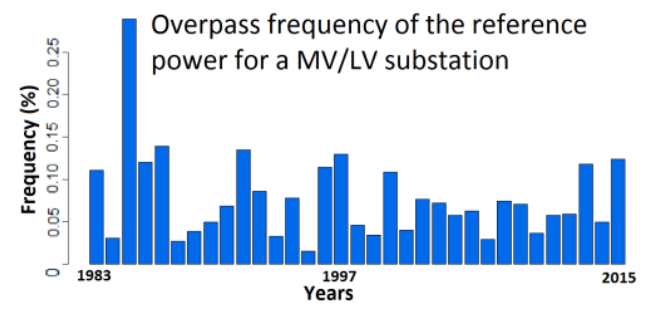

Figure 9 - Frequency (\%) of overpass of the reference power in a MV/LV substation with 30 meteorological years

\section{CONCLUSION}

Enedis and Mines Paris have developed the basics of a new innovative bottom-up load forecast and grid development method at local level. The first results obtained and the success observed by growing expectations from local authorities incentivize Enedis to further develop and finalize MOSAIC.
Enedis therefore continue to improve its methods (larger area, demand response, electric vehicle), the modeling parameters and the interactions with load flow computation by applying the MOSAIC method on ten areas of France. Thanks to MOSAIC, Enedis will be able to integrate in its planning methods local specificities such as economical or urban planning decisions. Furthermore, MOSAIC makes possible to run successively different scenarios. Therefore, for important projects, the local government will have feedbacks on the potential impact of its development project early in the project life cycle. This knowledge can help to make the best decision for the energy transition. MOSAIC won't replace Enedis' traditional planning methods. However, it can improve them especially when radical changes in future area makes it impossible to rely on past consumption trend.

\section{Acknowledgments}

The authors tank Hugues Souchard de Lavoreille and Maxence Leroy for their important contribution in the development of the Majic/Enedis matching method, the adaptation to MOSAIC and for the Brest case study results.

\section{REFERENCES}

[1] A. Mutanen, M. Ruska, S. Repo, and P. Jarventausta. Customer classification and load profiling method for distribution systems. IEEE Transactions on Power Delivery, 26(3):1755-1763, July 2011.

[2] T. Muneer, 1997, Solar radiation and daylight models for the energy efficient design of buildings, Architectural Press.

[3] A. Rogeau, R. Girard, T. Barbier, N. Kong, 2017, "Evolution of electrical distribution grids sizing considering self-consumption of local renewable production", Proceedings CIRED conference.

[4] T. Barbier, R. Girard, N. Kong et al, 2016, "An optimisation algorithm for matching large scale databases on customers for improved characterisation of electricity consumption". Proceedings MedPower 2016 conference.

[5] T. Barbier, R. Girard, F-P. Neirac, N. Kong and G. Kariniotakis, 2014, "A novel approach for electric load curve holistic modelling and simulation", Proceedings MEDPOWER 2014 conference.

[6] Ademe, EDF, Enertech, 2009, "Campagne de mesures des appareils de production de froid et des appareils de lavage dans 100 logements“. AEE2008 Project. Final report. 